\title{
The Gas Distribution Law in a Coal Mine in Shaanxi, China
}

\author{
Zhao Lei $^{1,}$, , Qu Shaodong ${ }^{1,2,3,4}$ \\ ${ }^{1}$ Shaanxi Provincial Land Engineering Construction Group Co., Ltd. Xi'an 710075 \\ ${ }^{2}$ Institute of Land Engineering and Technology, Shaanxi Provincial Land Engineering Construction \\ Group Co., Ltd. Xi'an 710075 \\ ${ }^{3}$ Key Laboratory of Degraded and Unused Land Consolidation Engineering, the Ministry of Land \\ and \\ Resources Xi'an 710075 \\ ${ }^{4}$ Shaanxi Provincial Land Consolidation Engineering Technology Research Center Xi'an 710075 \\ a359979246@qq.com
}

Keywords: Gas; Stratigraphic characteristics; Microface; Trap

Abstract. Aiming at the abnormal emission of coal seam floor gas in a Coal mine, we implemented the core drilling. Observed the lithology and gas emission information of the target, and combined with the previous studies, we conclude that there are three kinds of sedimentary microfacies in this working face floor: distant bar, estuary sand bar and swamp microfacies. And the gas trap types belongs to the tectonic-lithologic trap.

\section{Introduction}

Ordos basin is a basin formed in Late Triassic Mesozoic[1], the tectonic deformation of the basin is strong in edge, but the internal tectonic deformation is weak[2].A coal mine in Shaanxi is located in the south of Ordos Basin, in recent years, in the process of coal mining, the gas emission can cause some hidden danger to the coal mine production.

Comparison and division of formation is the basic geological research, through the stratigraphic division and correlation of the strata distribution can be achieved on the understanding of the situation, and the research of sedimentary facies is to explain the formation of gas occurrence regularity and has very important significance[3,4]. In the mining area, most of the Mesozoic gas occurrence is controlled by lithology and structure, the development and distribution of the reservoir is obviously affected by the sedimentary environment and the distribution of sand body[5,6]. Therefore, this paper intends to research 203 working face of coal seam floor of the 50m range of stratigraphic correlation and division.

\section{3 working face profile}

203 working face is located in the northeast of mine, The tectonic position is a small anticline, strike to the North West - South East, according to the 3D seismic exploration results show that the area is not have large faults. In order to study the lithology, structure and gas emission of 50m under the 203 working face floor, a total of 5 boreholes were drilled, which were HLJX-10, HLJX-11, HLJX-12, HLJX-13 and 20304(Fig. 1).

203 Working face

Fig. 1 Borehole location map of 203 working face 


\section{Stratigraphic correlation and division}

Single borehole analysis. The 20304 drill holes are described in detail. The hole is deep and the core rate is high, which depth is $70.84 \mathrm{~m}$, the drilling dip angle is 45 degrees, vertical depth is $50.09 \mathrm{~m}$. The formation of from top to bottom are Yanan formation, Fuxian formation and Wayaobu formation. Yanan formation, Below the coal seam is mudstone, the thickness of which is $1.02 \mathrm{~m}$. Fuxian formation(Fig. 2), the thickness is $26.02 \mathrm{~m}$, interbedded sandstone and mudstone, which Containing gas. Wayaobu formation, for fine sandstone, which Containing oil(Fig. 3).

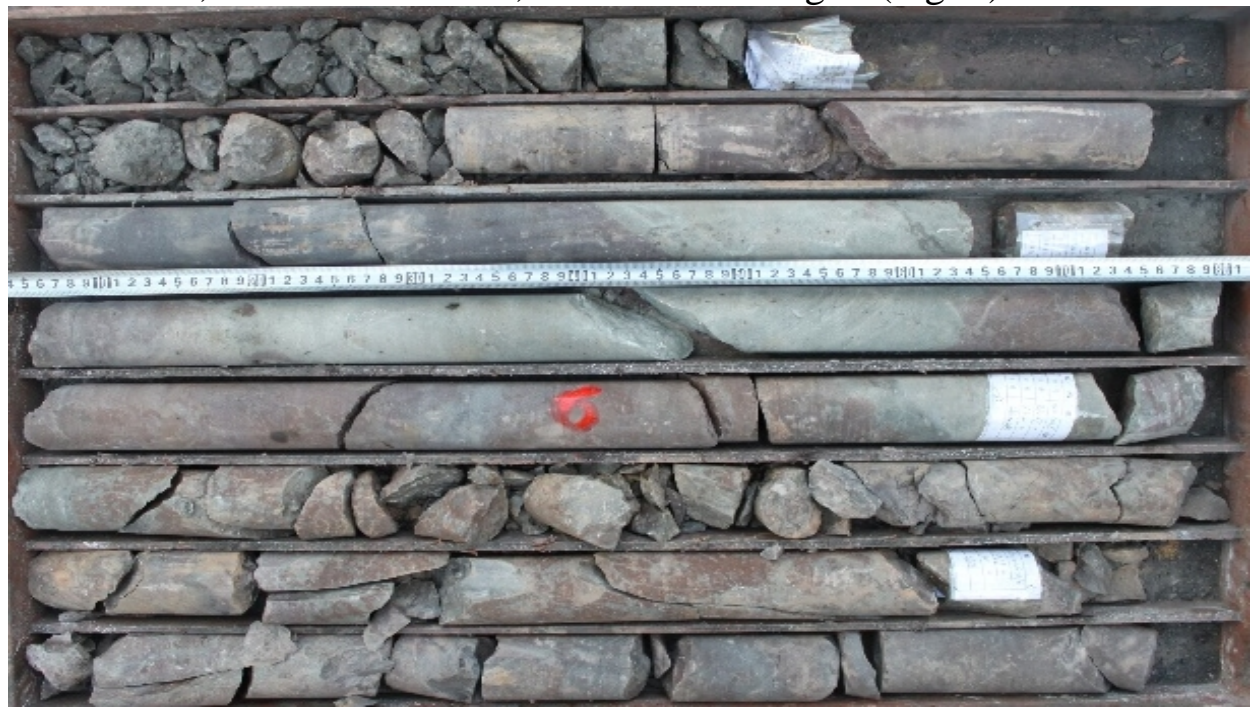

Fig. 2 The thick sandstone in upper Fuxian formation

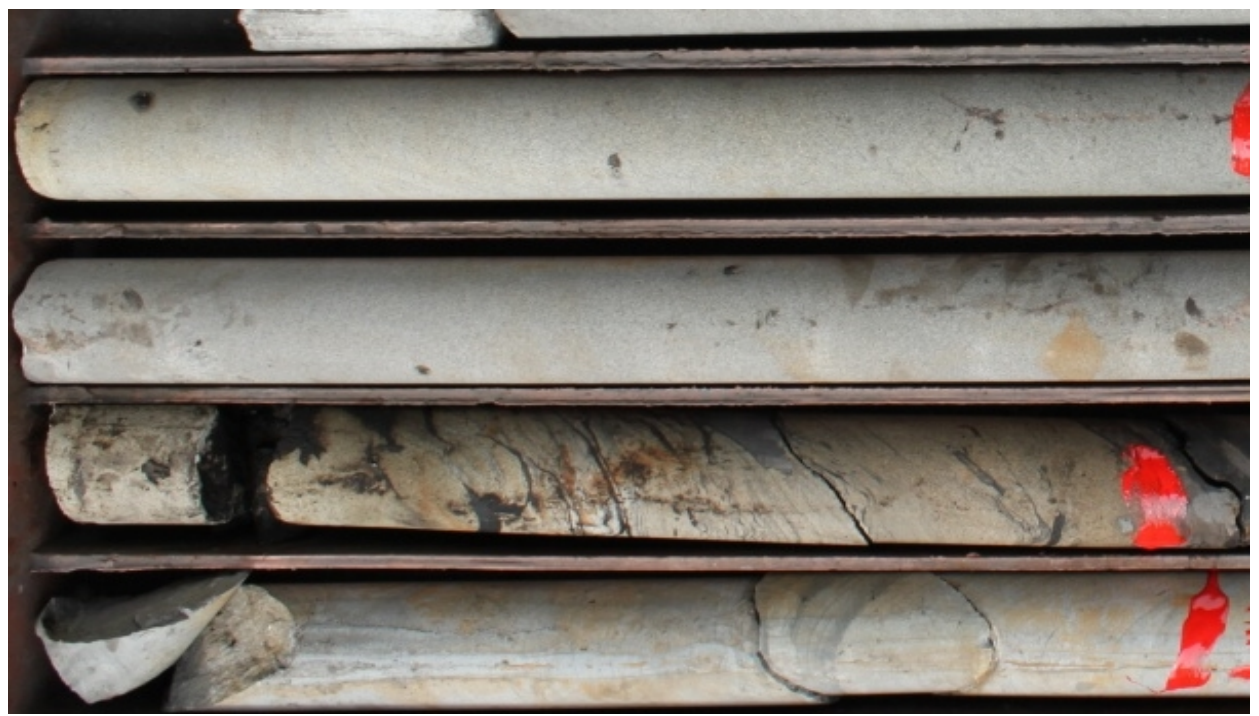

Fig. 3 The oil in sandstone in upper Wayaobu formation

Sedimentary analysis. Sedimentary analysis, mainly refers to the use of sedimentary cycles, lithology, stratigraphic thickness, to Comprehensive analysis[7]. In the study area, the structure of coal seam floor is weak, the formation is smooth, and the lithology of each layer is similar, so it can be combined with the thickness and elevation of the strata to analysis.

The coal seam of 203 work face strata division and correlation results. The strata of $50 \mathrm{~m}$ below coal seam are compared, we made the cross section in 203 working face(Fig. 4). Partition result display that a downward trend from the outside, the Yanan formation is thicker and the lithology changes from siltstone to mudstone. The Fuxian formation, which under the Yanan formation is thicker and the lithology changes from siltstone to mudstone too. 


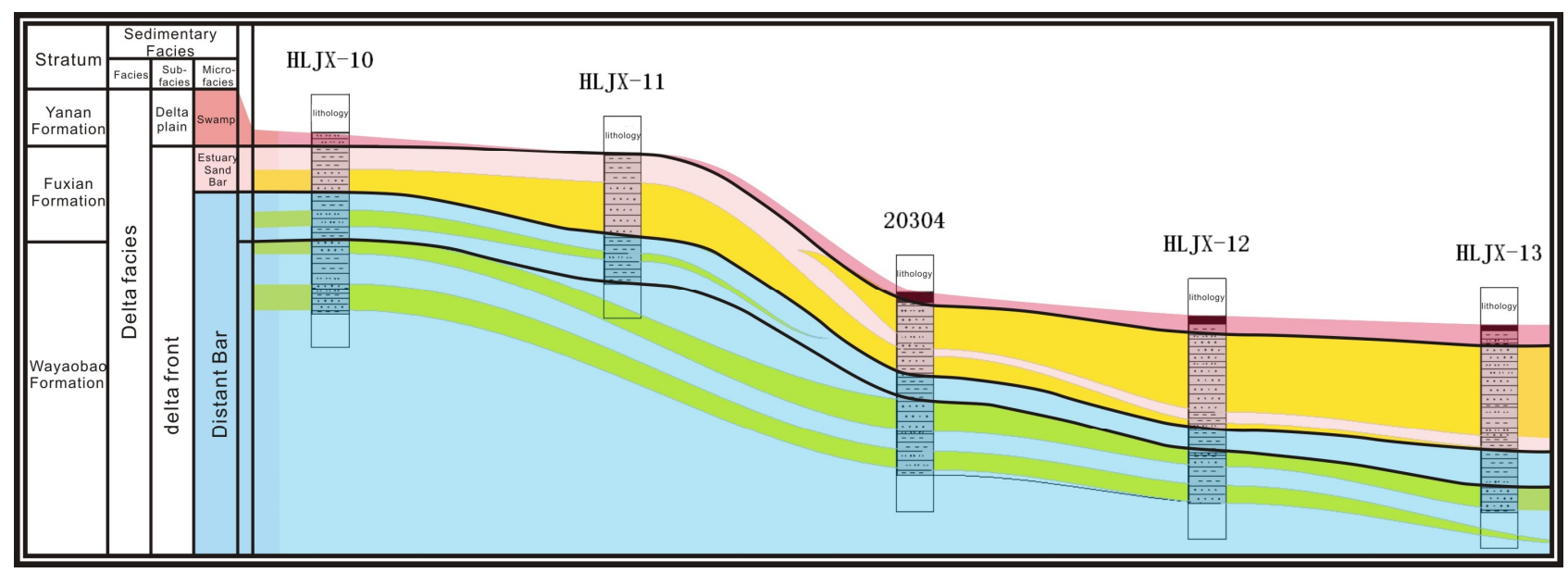

Figure 4 Stratigraphic correlation and microfacies analysis in 203 working face

\section{Sedimontary micro-facies analysis}

The analysis of sedimentary microfacies must depend on a large amount of core data and logging curves, and step by step under the premise of identifying large facies and subfacies. Core is the most direct, comprehensive and detailed first-hand information in geological research. It is also the most important information for the study of underground sedimentary facies.

203 working face of core holes are evenly arranged in the roadway, in core wells single well facies analysis, through the core observation and description in detail, combined with the analysis of experimental data of late, from the color, structure, lithology, cyclicity, authigenic minerals and fossils in the sedimentary characteristics analysis, combined with the regional sedimentary background, according to the rock section structure and sedimentary environment evolution rules, determine the research target bed of subfacies and microfacies, rock facies, to analysis the single well facies.

After analysis, the study area of Fuxian formation and Wayaobu formation belongs to delta front subfacies, the bottom of the Yanan group belongs to the delta plain facies. There are three kinds of microfacies in the study area: distant sand bar and estuary sand bar microfacies, swamp microfacies(Fig. 4).

From the bottom to the bottom, the microfacies of 203 working face are distant bar, estuary sand bar and swamp microfacies. The sedimentary facies sequence is not complete due to the small section range and shallow vertical depth. Microfacies change reflects the characteristics of delta front and subfacies, and has the trend of changing to the shore and shallow lake subfacies. However, there are some differences in the development degree and the pre production range of delta front facies in different periods.

\section{Analysis of main control factors and distribution law of gas}

Analysis of main control factors of gas. According to the gas logging data show that gas occurs mainly in the top of the sand rock in Fuxian formation, due to thin, and lower lithology with mottled purple mudstone, organic matter content is low, do not have the conditions for hydrocarbon generation. The gas of Fuxian formation in sandstone mainly formen in Yanchang Formation in Erdos basin[8-11].The gas migration channels include the unconformities and the thick sand bodies between the Jurassic and the Triassic System[12]. The 203 working face is a slope, and the gas is enriched on the slope in the middle of the working face, which belongs to the tectonic slope zone.The sandstone reservoir of Fuxian formation development of estuary sand bar microfacies sedimentary, which are high porosity sandstone, can serve as a good reservoir. In the sandstone updip direction, containing a large amount of gas. It is covered with thick layers of mudstone, it is a lithologic trap, which has a good blocking effect on the migration of oil and gas. Comprehensive analysis shows that the 
occurrence of coal seam floor in 203 working faceis mainly controlled by structure and lithology, it' s a typical tectonic lithologic trap(Fig. 5).

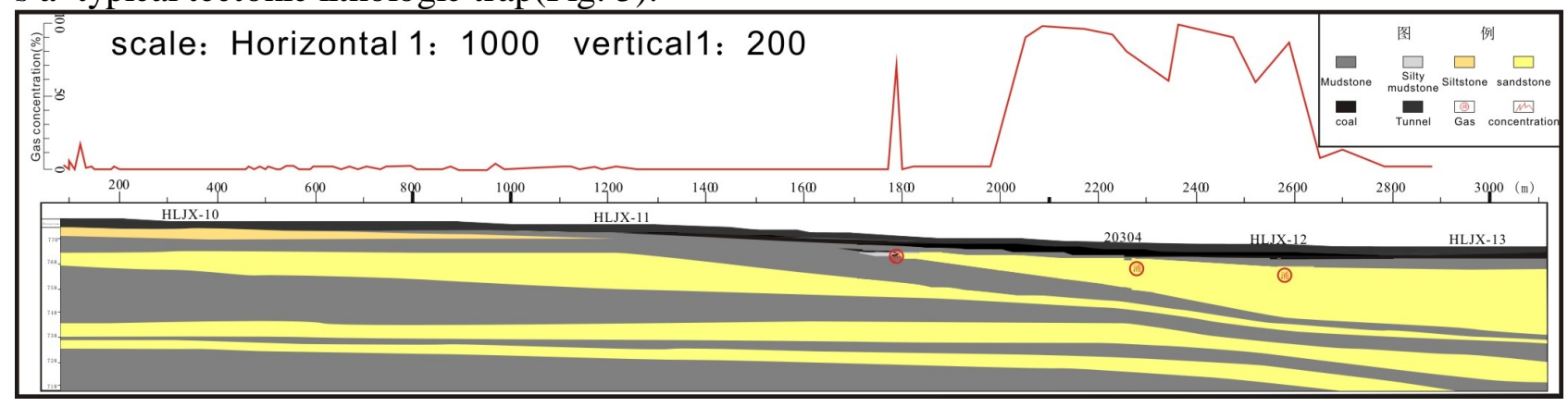

Figure 5 The well profile of underground coring hole in 203 working face

\section{Prediction of gas distribution law}

It is of great significance for the safe production of coal mine to do the prediction of the law of gas distribution. The sediment size in coal mine is fine in general, But in the area of fine sandstone, gas is easy to gather because of the good physical property.Especially at the high point of construction, that is, the upper end of the sandstone, the gas is easily aggregated. Therefore, it is considered that the location where the fine sandstone development is located on the top tip of the sandstone the gas is easy to gather. In the process of subsequent mining of coal mine, we should pay special attention to it.

\section{conclusion}

1. From the bottom to the bottom, the microfacies of 203 working face are distant bar, estuary sand bar and swamp microfacies. The sedimentary facies sequence is not complete due to the small section range and shallow vertical depth. Microfacies change reflects the characteristics of delta front and subfacies, and has the trend of changing to the shore and shallow lake subfacies. However, there are some differences in the development degree and the pre production range of delta front facies in different periods.

2. The gas is stored in the middle of the 203 working face of Fuxian formation, the lithology of the reservoir is fine grained sandstone, and it is enriched in the upper dip point of the sandstone. Which show that the gas are controlled by structure and lithology, it' s a typical tectonic lithologic trap. The top dip end of fine grained sandstone can also be used as an important index for predicting gas enrichment.

3. As a low cost and high efficiency method, underground drilling can quickly and effectively determine the sedimentary microfacies of coal seam floor, analyze reservoir distribution and structure rules, and accurately locate and predict gas occurrence sites, which can provide security for the safe production of the coal mine。

\section{References}

[1] Y.Duan, Bx. Wu, Cy.Zheng, Cy.Wang. Pool-forming dynamic properties of Xifeng Oil field in Ordos Basin. Acta Petrolei Sinica. 4. 29-33 (2005), P. 26

[2] Zl.Ren, Cy.Zhao, J.Zhang, Zp.Yu. Research on paleotemperature in the Ordos Basin. Acta Sedimentologica Sinica. 1. 56-65 (1994), P. 12

[3] M.Wang. Comparison method of continental sedimentary strata, (Petroleum Industry Press, Beijing 2011).

[4] Gx.Shi, Jf.Liu. Study on sedimentary facies of the Yan 9 formation of the southern Ansai Oilfield. Journal of Oil and Gas Technology. 1. 184-187 (2010), P. 32 
[5] Zq.Guo, Lr.Zhang, Mj.Chu, Jx.Huang. Pre-Jurassic palaeogeomorphic control on the hydrocarbon accumulation in the lower Yan'an formation in southern Ordos basin. Journal of Palaeogeography. 1. 63-71 (2008), P. 10

[6] Lq.Liu, Jp.Liu, Y.Li, Mz.Wei. Main factors influencing oil reservoir in jurassic Yan' an formation in Pengyan area, Ordos basin.Journal of Earth Sciences and Environment. 3. 263-267 (2010), P. 32

[7] Xq.Ding, Sn.Zhang. Sequence stratigraphy analysis of Yan'an Formation in the southwest of Ordos Basin,China. Journal of Chengdu University of Technology(Science\&Technology Edition). 6. 681-685 (2008), P. 35

[8] B.Wei, H.Wei, Q.Chen. Sediment provenance analysis of Yanchang Formation in Ordos Basin. Journal of Northwest University. 4. 447-450 (2003), P. 33

[9] F.Wu, W.Li, Y.Li. Delta sediments and evolution of the Yanchang Formation of Upper Triassic in Ordos Basin. Journal of Palaeogeography. 3. 307-315 (2004), P. 6

[10]D.B.Brinkman, J.H.Peng. Ordosemys leios, n.gen. n.sp. a new turtle from the Early Cretaceous of the Ordos Basin, Inner Mongolia. Canadian Journal of Earth Sciences. 10. 2128-2138 (1993), P. 30

[11]S.Dai, D.Ren, C.L.Chou. Mineralogy and geochemistry of the No. 6 Coal (Pennsylvanian) in the Junger Coalfield, Ordos Basin, China. International Journal of Coal Geology. 4. 253-270 (2006), P. 66

[12] Wz.Zhang, H.Yang, Jf.Lil. Leading effect of high-class source rock of Chang 7 in Ordos Basin on enrichment of low permeability oil-gas accumulation-Hydrocarbon generation and expulsion mechanism. Petroleum Exploration \& Development. 3. 289-293 (2006), P. 33 